\title{
Distribution of liposome-encapsulated antimony in dogs
}

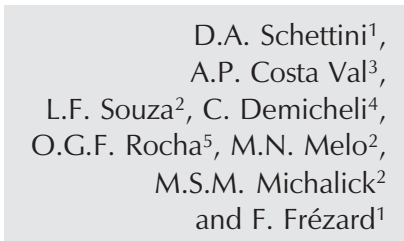

\author{
Departamentos de ${ }^{1}$ Fisiologia e Biofísica, and ${ }^{2}$ Parasitologia, Instituto de Ciências \\ Biológicas, ${ }^{3}$ Departamento de Clínica e Cirurgia Veterinárias, Escola Veterinária, \\ and ${ }^{4}$ Departamento de Química, Instituto de Ciências Exatas, \\ Universidade Federal de Minas Gerais, Belo Horizonte, MG, Brasil \\ ${ }^{5}$ Laboratório de Análise de Traços Metálicos, CETEC, Belo Horizonte, MG, Brasil
}

\author{
Correspondence \\ F. Frézard \\ Departamento de Fisiologia \\ e Biofísica, ICB, UFMG \\ Av. Antônio Carlos, 6627 \\ 31270-901 Belo Horizonte, MG \\ Brasil \\ Fax: +55-31-3499-2924 \\ E-mail: frezard@mono.icb.ufmg.br \\ Presented at the XXVIII Annual \\ Meeting on Basic Research in Chagas \\ Disease, November 5-7, 2001, and \\ at the XVII Annual Meeting of the \\ Federação de Sociedades de Biologia \\ Experimental, Salvador, BA, Brazil, \\ August 28-31, 2002. \\ Research supported by CNPq (Nos. \\ 521010/97 and 471902/2001-2), \\ FAPEMIG (CEX 339/01), FAPEBIO/ \\ UFMG and FINEP (Pronex). \\ D.A. Schettini is the recipient of a \\ studentship from CNPq. \\ $\ldots \ldots \ldots \ldots \ldots \ldots$
}

Received April 11, 2002

Accepted November 7, 2002

$\ldots \ldots \ldots \ldots \ldots \ldots$

\begin{abstract}
The achievement of complete cure in dogs with visceral leishmaniasis is currently a great challenge, since dogs are the main reservoir for the transmission of visceral leishmaniasis to humans and they respond poorly to conventional treatment with pentavalent antimonials. In order to improve the efficacy of treatment, we developed a novel formulation for meglumine antimoniate based on the encapsulation of this drug in freeze-dried liposomes (LMA). The aim of the present study was to evaluate the biodistribution of antimony ( $\mathrm{Sb}$ ) in dogs following a single intravenous bolus injection of LMA. Four healthy male mongrel dogs received LMA at $3.8 \mathrm{mg} \mathrm{Sb} / \mathrm{kg}$ body weight and were sacrificed 3, 48 and $96 \mathrm{~h}$ and 7 days later. Antimony was determined in the blood, liver, spleen and bone marrow. In the bone marrow, the highest $\mathrm{Sb}$ concentration was observed at $3 \mathrm{~h}(2.8 \mu \mathrm{g} / \mathrm{g}$ wet weight) whereas in the liver and spleen it was demonstrated at $48 \mathrm{~h}$ (43.6 and $102.4 \mu \mathrm{g} / \mathrm{g}$, respectively). In these organs, Sb concentrations decreased gradually and reached levels of $19.1 \mu \mathrm{g} / \mathrm{g}$ (liver), $28.1 \mu \mathrm{g} / \mathrm{g}$ (spleen) and $0.2 \mu \mathrm{g} / \mathrm{g}$ (bone marrow) after 7 days. Our data suggest that the critical organ for the treatment with LMA could be the bone marrow, since it has low Sb levels and, presumably, high rates of $\mathrm{Sb}$ elimination. A multiple dose treatment with LMA seems to be necessary for complete elimination of parasites from bone marrow in dogs with visceral leishmaniasis.
\end{abstract}

Key words

- Liposomes

- Meglumine antimoniate

- Biodistribution

- Leishmaniasis

- Dogs
The leishmaniases are a group of diseases produced by invasion of the reticuloendothelial system of a mammalian host by a parasite of the genus Leishmania. This parasite is found as a motile promastigote in the sand fly and transforms into an amastigote when engulfed by host macrophages (1). Visceral leishmaniasis is the most severe form of the disease, causing human death if not treated.

The first line drugs for the treatment of leishmaniasis are the pentavalent antimoni- als, including meglumine antimoniate (2). Although these drugs usually lead to cure in humans, they produce only a transitory improvement in dogs with visceral leishmaniasis (3), the main reservoir for the transmission of visceral leishmaniasis to humans. Because of the risk of development of parasite resistance to antimonials, the World Health Organization no longer recommends antimonial therapy for dogs. In this context, the achievement of complete cure in infected 
dogs remains one of the greatest challenges for the control of the disease.

The use of liposomes represents a promising strategy, since this form of delivery considerably enhances the efficacy of antimonials against visceral leishmaniasis (4). This effect was attributed to the ability of liposomes to prolong the presence of the drug within the organism as well as to deliver it specifically to the sites of parasite location, i.e., the liver, spleen, and bone marrow. Recently, our group carried out the synthesis of the pentavalent antimonial drug, meglumine antimoniate, as well as its formulation in multilamellar liposomes, using novel methods that were shown to be simpler and more efficient than conventional ones $(5,6)$. One of the resulting formulations, which consisted of meglumine antimoniate encapsulated in freeze-dried liposomes (LMA), could be stored as intermediate lyophilized powder and reconstituted just before use. This represents a major advantage over conventional formulations that can be stored only as aqueous liposome suspensions and exhibit stability problems in these conditions $(4,7)$. Furthermore, LMA showed the expected high antileishmanial activity in hamsters experimentally infected with Leishmania (Leishmania) chagasi (6).

In order to determine the most appropriate dose of LMA for the treatment of visceral leishmaniasis in dogs, as a first step, we investigated the biodistribution of antimony $(\mathrm{Sb})$ in dogs following intravenous (iv) administration of LMA.

Meglumine antimoniate was synthesized as previously described (5) from equimolar amounts of $\mathrm{N}$-methyl glucamine and pentavalent oxyhydrated antimony. The resulting product contained approximately $30 \%$ antimony by weight, as determined by atomic absorption spectroscopy.

Meglumine antimoniate was encapsulated in freeze-dried liposomes as previously described (6). Briefly, small unilamellar vesicles were prepared in water from L- $\alpha$-distearoyl- phosphatidylcholine, cholesterol and dicetylphosphate (molar ratio of 5:4:1) at the final lipid concentration of $55 \mathrm{~g} / 1$. This suspension was frozen and subsequently lyophilized overnight. Rehydration of the dried powder was performed with an aqueous LMA solution ( $\mathrm{Sb}$ concentration of $80 \mathrm{~g} / \mathrm{l}$ ) and phosphate-buffered saline (PBS, $150 \mathrm{mM} \mathrm{NaCl}$, $10 \mathrm{mM}$ phosphate, $\mathrm{pH}$ 7.2) as follows: $40 \%$ of the original small unilamellar vesicle volume of the LMA solution was added to the lyophilized powder and the mixture was incubated for $30 \mathrm{~min}$ at $55^{\circ} \mathrm{C}$; the same volume of PBS was then added and the mixture was incubated for $30 \mathrm{~min}$ at $55^{\circ} \mathrm{C}$. Drug-containing liposomes were separated from the nonencapsulated drug by centrifugation at 10,000 $g$ for $30 \mathrm{~min}$. The liposome pellet was then washed twice and finally resuspended in PBS. The amount of $\mathrm{Sb}$ was determined in the resulting liposome suspension by plasma emission spectroscopy using a Perkin-Elmer (Shelton, CT, USA) Optima 3000 plasma emission spectrometer (ICP AES). The encapsulation of meglumine antimoniate was achieved with a trapping efficiency of 38\% and an Sb/lipid ratio of $0.175(w / w)$. The vesicular suspension was sized by photon correlation spectroscopy at a $90^{\circ}$ scattering angle using a channel correlator (type 4700, Malvern Instruments, Worcestershire, UK) in combination with an $\mathrm{He} / \mathrm{Ne}$ laser (wavelength $633 \mathrm{~nm}$, nominal power output 32 $\mathrm{mW}$ ). The mean hydrodynamic diameter of the vesicles was $2.37 \mu \mathrm{m}$, with a polydispersity factor of 0.5 .

To evaluate the biodistribution of $\mathrm{Sb}$ in dogs following the administration of LMA, four healthy male mongrel dogs weighing 8 to $12 \mathrm{~kg}$, obtained from the Centro de Zoonoses, Prefeitura Municipal de Belo Horizonte, MG, Brazil, received LMA as a single dose of $3.8 \mathrm{mg} \mathrm{Sb} / \mathrm{kg}$ by the $i v$ route. Animals were negative to serological tests for Leishmania (data not shown) such as indirect immunofluorescence, complement fixation test and enzyme-linked immunosor- 
bent assay. Animals were sacrificed 3, 48 and $96 \mathrm{~h}$ and 7 days after administration. A barbituric drug (sodium pentobarbital) was used for humane euthanasia of the dogs, as described by Smith et al. (8) and as routinely used at the Veterinary Hospital of UFMG.

The liver, spleen, bone marrow and blood were recovered and submitted to digestion with nitric acid in a microwave oven (CEM, MDS 200). The amount of Sb was then determined as previously described (9), using a Perkin-Elmer Z5100 graphite furnace atomic absorption spectrometer. All analyses were performed using a continuous background correction. The analytical method was validated according to the following steps: i) determination of the working concentration range; ii) verification of the linearity of the calibration function; iii) verification of the selectivity of the method; iv) evaluation of the recovery after the addition of standards; v) determination of the instrument and method detection limits (10).

It is noteworthy that LMA did not produce any significant clinical alterations in dogs following its $i v$ administration at 3.8 $\mathrm{mg} \mathrm{Sb} / \mathrm{kg}$ body weight. This is important, as the dose of $\mathrm{Sb}$ used in the present study is relatively high when compared to those given to dogs in previous studies with other antimony-containing liposome formulations. Among the three studies published until now (11-13), with pentavalent antimonials encapsulated in liposomes administered $i v$ to dogs, only the most recent one (13) used a higher dose of $\mathrm{Sb}(9.8 \mathrm{mg} / \mathrm{kg})$.

Figure 1 shows the $\mathrm{Sb}$ concentrations determined in the liver, spleen and bone marrow of dogs at different times after the $i v$ administration of LMA. In the bone marrow, the highest $\mathrm{Sb}$ concentration was observed at $3 \mathrm{~h}(2.8 \mu \mathrm{g} / \mathrm{g}$ wet weight), whereas in the liver and spleen it was observed at $48 \mathrm{~h}(43.6$ and $102.4 \mu \mathrm{g} / \mathrm{g}$, respectively). Antimony concentrations in these tissues then decreased gradually and reached levels of $19.1 \mu \mathrm{g} / \mathrm{g}$ (liver), $28.1 \mu \mathrm{g} / \mathrm{g}$ (spleen) and $0.2 \mu \mathrm{g} / \mathrm{g}$ (bone marrow) after 7 days.

The extent of drug targeting achieved with the present liposome formulation can be assessed by comparing our results to those obtained in a previous study following iv administration to dogs of a free pentavalent antimonial drug at $45 \mathrm{mg} \mathrm{Sb} / \mathrm{kg}$ (12). Remarkably, the Sb concentrations achieved in the spleen and liver $48 \mathrm{~h}$ after the injection of our liposome formulation were about 50fold and 6-fold higher, respectively, than those reached after $48 \mathrm{~h}$ in the same organs after administration of the free drug. On the other hand, in the bone marrow, about the same levels were achieved after $48 \mathrm{~h}$. Our results therefore suggest that a single dose treatment with LMA may not be sufficient to induce complete elimination of parasites from the bone marrow of dogs.

The present results can also be compared to those obtained following iv injection in dogs of another vesicular system with a 6fold lower dose of $\mathrm{Sb}$ (12). In our study, higher $\mathrm{Sb}$ levels were achieved in the spleen and liver but a lower level was found in the bone marrow. The relatively low $\mathrm{Sb}$ level observed in the bone marrow may be attributed to the larger size of our liposomes (2.37 $\mu \mathrm{m})$ compared to those previously used $(0.12$ $\mu \mathrm{m})$, and to the fact that bone marrow is expected to be more accessible to smaller liposomes (14).

From the data presented in Figure 1, the rate of $\mathrm{Sb}$ elimination could be inferred for the different organs. In the bone marrow, the rate of elimination was about 1.7 -fold and 2.6-fold higher than in the spleen and liver,

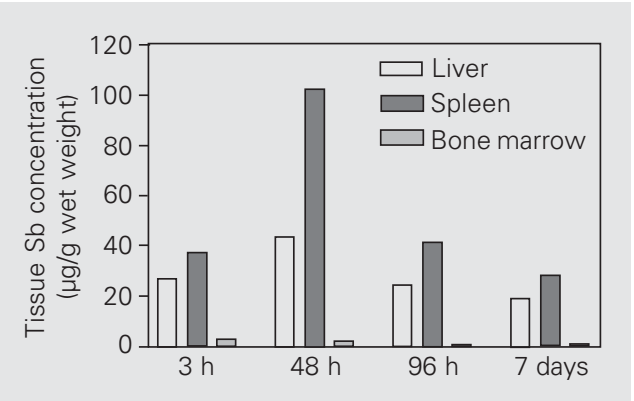

Figure 1. Distribution of antimony (Sb) concentrations determined in the liver, spleen and bone marrow of dogs at different times after a single intravenous bolus injection of liposome-encapsulated meglumine antimoniate at $3.8 \mathrm{mg} \mathrm{Sb} / \mathrm{kg}$ body weight. 
respectively.

In blood, Sb concentration remained relatively constant at about $100 \mathrm{ng} / \mathrm{ml}$ (data not shown). This concentration is very low when compared to the peak Sb concentration (128 $\mu \mathrm{g} / \mathrm{ml}$ ) achieved in the blood of dogs $20 \mathrm{~min}$ after a single $i v$ injection of the free drug at $45 \mathrm{mg} \mathrm{Sb} / \mathrm{kg}$ (12). This low Sb level can be explained both by the fast clearance of LMA by the liver and spleen and by the rapid renal elimination of free antimonial drug (12).

The present data indicate that a single $i v$ bolus injection in dogs of LMA at $3.8 \mathrm{mg}$ $\mathrm{Sb} / \mathrm{kg}$ resulted in high $\mathrm{Sb}$ levels in the liver and spleen for a long period of time and also suggest that the critical organ for treatment with LMA could be the bone marrow since this organ showed low Sb levels and, presumably, high Sb elimination. Finally, the present study suggests that a multiple dose treatment with LMA seems to be necessary for the complete elimination of parasites from the bone marrow in dogs with visceral leishmaniasis.

\section{Acknowledgments}

We are indebted to Dr. Maria Helena Andrade Santana (DPB, FEQ, UNICAMP, Campinas, SP, Brazil) for the determination of liposome size.

\section{References}

1. Alexander A \& Russel DG (1992). The interaction of Leishmania species with macrophages. Advances in Parasitology, 31: 175-254.

2. Marsden PD (1985). Pentavalent antimonials: old drug for new diseases. Revista da Sociedade Brasileira de Medicina Tropical, 18: 187-198.

3. Alvar J, Molina R, San Andrés M, Tesouro M, Nieto J, Vitutia M, Gonzalez F, San Andrés MD, Boggio J, Rodriguez F, Sainz A \& Escacena C (1994). Canine leishmaniasis: clinical, parasitological and entomological follow-up after chemotherapy. Annals of Tropical Medicine and Parasitology, 88: 371-378.

4. Alving CR (1986). Liposomes as drug carriers in leishmaniasis and malaria. Parasitology Today, 2: 101-107

5. Demicheli C, de Figueiredo TL, Carvalho S, Sinesterra RD, Lopes JC \& Frézard $F$ (1999). Physico-chemical characterization of meglumine antimoniate. Biometals, 12: 63-66.

6. Frézard F, Michalick MSM, Soares CF \& Demicheli C (2000). Novel methods for the encapsulation of meglumine antimoniate in liposomes. Brazilian Journal of Medical and Biological Research, 33: 841-846.

7. Rao LS (1986). Antileishmanial Pharmaceutical Formulation. US Patent, No. 4,594,241.

8. Smith AW, Houpt KA, Kitchel RL, Konh DF \& MacDonald LE (1986). American Veterinary Medical Association Panel of Euthanasia. Journal of the American Veterinary Medical Association, 8: 252-268.
9. Costantini S, Giordano R, Rizzica M \& Benedetti F (1985). Applicability of anodic-stripping voltammetry and graphite furnace atomicabsorption spectrometry to the determination of antimony in biological matrices: a comparative study. Analyst, 110: 1355-1359.

10. Glaser JA, Foerst DL, McKee GD, Quave SA \& Bedde WL (1981). Trace analyses for wastewaters. Environmental Science and Technology, 15: 1426-1435.

11. Chapman WL, Hanson WL, Alving CR \& Hendricks LD (1984). Antileishmanial activity of liposome-encapsulated meglumine antimoniate in the dog. American Journal of Veterinary Research, 45: 1028-1030.

12. Collins M, Carter KC, Baillie AJ \& O'Grady J (1993). The distribution of free and non-ionic vesicular sodium stibogluconate in the dog. Journal of Drug Targeting, 1: 133-142.

13. Valladares JE, Riera C, González-Ensenyat P, Díez-Cascon A, Ramos G, Solano-Gállego L, Gállego M, Portús M, Arboix M \& Alberola J (2001). Long-term improvement in the treatment of canine leishmaniosis using an antimony liposomal formulation. Veterinary Parasitology, 97: 15-21.

14. Carter KC, Dolan TF, Alexander J, Baillie AJ \& McColgan C (1989) Visceral leishmaniasis: drug carrier characteristics and the ability to clear parasites from the liver, spleen and bone marrow in Leishmania donovani infected BALB/c mice. Journal of Pharmacy and Pharmacology, 41: 87-91. 